\title{
Influence of Waste Slurry as Mixing Water on the Properties of C80 Concrete with Different Mineral Admixtures
}

\author{
Changbing Chen*, Pengcheng Tang, Jingjing Zhuang \\ Hefei University, Hefei 230601, China
}

Corresponding Author Email: czb1108@hfuu.edu.cn

https://doi.org/10.18280/acsm.440404

Received: 17 April 2020

Accepted: 15 July 2020

\section{Keywords:}

waste slurry, mixing station, high-performance concrete, mineral admixture.

\begin{abstract}
This paper mainly explores how waste slurry as mixing water affects the properties of C80 concrete. The waste slurry was collected from a mixing station. Two types of C80 concrete were prepared with different mineral admixtures: type I concrete mixed from $15 \%$ fly ash and $20 \%$ slag powder, and type II concrete mixed from $20 \%$ fly ash and $10 \%$ silica fume. The properties of the two types of concrete were evaluated in terms of working performance, mechanical properties, and durability. In addition, the influence of waste slurry on microstructure of concrete was analyzed through X-ray diffraction (XRD). The results show that, with the growing content of waste slurry, slump and expansion were declining; the initial and final setting times gradually increased, but the increments were not significant; with the growing content of waste slurry, the $7 \mathrm{~d}$ compressive strength of type I concrete stayed below that of reference concrete, and gradually decreased, but the later compressive strengths increased rapidly; the $7 \mathrm{~d}$ compressive strength of type II mineral admixture concrete gradually increased, while the later compressive strengths increased first and then decreased. Besides, the addition of waste slurry enhanced the resistance to chloride ion penetration (CIP), and increased the carbonization depth of concrete. The $7 \mathrm{~d}$ XRD peak of using tap water as mixing water was slightly higher than that of using waste slurry as mixing water; the 28d XRD peak of the former was slightly lower than that of the latter. The research provides reference for applying waste slurry in concrete production.
\end{abstract}

\section{INTRODUCTION}

During the cleaning of concrete transport vehicles and mixing stations, lots of waste slurry and solid wastes are produced. Direct discharge of the waste slurry and solid wastes will seriously pollute water and soil, and even block the municipal pipe network, exerting a great impact on the normal life and work of residents [1].

The waste slurry, which mainly contains water, nonhydrated cement particles, and residual mineral admixtures/additives, is highly alkaline. The potential of hydrogen $(\mathrm{pH})$ of the waste slurry could reach 12 and above. With the growing awareness of environmental protection, it is urgent to recycle and reuse the waste slurry from mixing stations [2].

Mixing water is a vital material for concrete [3]. For a mixing station with an annual output of $500,000 \mathrm{~m}^{3}$, up to 80,000 tons of wastewater is discharged each year. Hence, a mixing station with an annual output of $200,000 \mathrm{~m}^{3}$ can only recycle and treat 60 tons of wastewater per day $[4,5]$.

Germany started to recycle concrete early in the 1980 s, and manages to increase the recycling rate of waste slurry to $95 \%$ [6]. In Japan, the solid waste is usually divided into waste aggregate and wastewater, and then recycled in concrete production; during the recycling, the solid content of the mixing water is controlled to less than $10 \mathrm{~kg} / \mathrm{m}^{3}$ [7]. In China, about $75 \%$ of waste slurry from mixing stations are recovered and reused.

As urbanization picks up speed, there is a growing demand for infrastructure construction. Therefore, the construction industry is in urgent need of high-performance building materials. High-performance concrete provides an ideal construction material, for its good working performance, mechanical properties, and durability. The properties of highperformance concrete depend on the selection of raw materials, admixtures, etc.

At present, the waste slurry produced in mixing stations is mostly processed into low-strength concrete. There is little report on how waste slurry affects the working performance, mechanical properties, and durability of recycled concrete [8]. Moreover, few attempts have been made to prepare highperformance concrete from waste slurry.

In this paper, waste slurry is mixed with tap water, and used as mixing water to produce recycled concrete. The effects of the mixing water on $\mathrm{C} 80$ concrete prepared by two mineral admixtures were investigated, in terms of working performance, mechanical properties, and durability. In addition, the influence of waste slurry on microstructure of concrete was analyzed through X-ray diffraction (XRD).

\section{TEST RAW MATERIALS}

The raw materials of this research are introduced as follows.

\subsection{Cement}

The cement is P.II52.5 type ordinary Portland cement, 
whose specific surface area (SSA) is $35 \mathrm{~m}^{2} / \mathrm{kg}$, loss on ignition (LOI) is $2.33 \%$, insoluble matter is $0.63 \%$, chloride ion content is $0.023 \%, 3 \mathrm{~d}$ compressive strength is $33.4 \mathrm{MPa}$, and $28 \mathrm{~d}$ compressive strength is $55.3 \mathrm{MPa}$.

\subsection{Coarse aggregate}

The coarse aggregate is crushed stones with good particle size distribution. The apparent density is $2,800 \mathrm{~kg} / \mathrm{m}^{3}$, the stacking density is $1,540 \mathrm{~kg} / \mathrm{m}^{3}$, the needle-like content is $4.0 \%$, and the mud content is $0.3 \%$.

\subsection{Fine aggregate}

The fine aggregate is medium sand, whose fineness modulus is 2.6 , mud content is $0.9 \%$, bulk density is $1,460 \mathrm{~kg} / \mathrm{m}^{3}$, and apparent density is $2,650 \mathrm{~kg} / \mathrm{m}^{3}$.

\subsection{Admixtures}

Three different admixtures are specified below:

(1) Class F grade I fly ash

The greyish brown fly ash was screened by a $45 \mu \mathrm{m}$ sieve. The fineness is $12 \%$, the water demand ratio is $91 \%$, the LOI is $3.4 \%$, the water content is $0.6 \%$, the density is $1.7 \mathrm{~g} / \mathrm{cm}^{3}$, and the strength activity index is $90 \%$.

(2) S95 grade slag powder

For the slag powder, the $3 \mathrm{~d}, 7 \mathrm{~d}$, and $38 \mathrm{~d}$ compressive strengths of cement are $26.6 \mathrm{MPa}, 36.4 \mathrm{MPa}$ and $52.6 \mathrm{MPa}$, respectively; the density is $2.92 \mathrm{~g} / \mathrm{cm}^{3}$, the SSA is $405 \mathrm{~m}^{2} / \mathrm{kg}$, the $7 \mathrm{~d}$ active index is $78 \%$, the initial setting time is $131 \%$, the flow ratio is $99 \%$, the chloride ion content is $0.01 \%$, and the LOI is $0.24 \%$.

(3) Silica fume

The silica fume has a greater than $91 \% \mathrm{SiO}_{2}$ content.

\subsection{Additives}

Two additives were selected, including PCA-1 polycarboxylate superplasticizer (water reduction rate: $30 \%$; solid content: $11.03 \%$; density: $\left.1.03 \mathrm{~g} / \mathrm{cm}^{3}\right)$, and BTC functional admixture (density: $1.007 \mathrm{~g} / \mathrm{cm}^{3} ; \mathrm{pH}$ : 9.7; chloride ion content: 0.008).

\subsection{Water and waste slurry}

Tap water ( $\mathrm{pH}: 7.1)$ is adopted for this research, plus the waste slurry from a mixing station in Hefei, the seat of Anhui Province, China.

\section{METHODOLOGY}

\subsection{Mix ratio design for $\mathrm{C} 80$ concrete}

After lab trials, the mix ratios of the two types of concretes were determined (Tables 1 and 2). The dosage of cementitious material was set to $600 \mathrm{~kg} / \mathrm{m}^{3}$. The slump was designed as $200 \pm 20 \mathrm{~mm}$. For type I mineral admixture, the fly ash content is $15 \%$, and the slag powder content is $20 \%$ of the total cementitious material. For type II mineral admixture, the fly ash content is $20 \%$, and the silica fume content is $10 \%$ of the total cementitious material.

Furthermore, the amount of mixing water was designed as follows: $0 \%$ waste slurry $+100 \%$ tap water; $20 \%$ Waste slurry $+80 \%$ tap water; $40 \%$ waste slurry $+60 \%$ tap water; $60 \%$ waste slurry $+40 \%$ tap water; $80 \%$ waste slurry $+20 \%$ tap water; $100 \%$ waste slurry $+0 \%$ tap water.

\subsection{Working performance and durability tests}

The working performance of the prepared concretes, including slump, expansion, and setting time, was tested according to Standard for Test Method of Performance on Ordinary Fresh Concrete (GB/T50080-2016) [9].

Drawing on Standard for Test Methods of Mechanical Properties on Ordinary Concrete (GB/T50081-2002) [10] and Technical Specification for High-Strength Concrete Structures (CECS104:99) [11], a total of 9 concrete blocks $(100 \mathrm{~mm} \times 100 \mathrm{~mm} \times 100 \mathrm{~mm})$ of each type of concrete were prepared. Three blocks were used for the test on $7 \mathrm{~d}$ compressive strength, three for the test on $28 \mathrm{~d}$ compressive strength, and three for the test on 56d compressive strength.

In addition, the durability of each block was measured as per Standard for Test Methods of Long-Term Performance and Durability of Ordinary Concrete (GB/T50082-2009) [12] and CECS104:99.

Table 1. The mix ratios of type I concrete

\begin{tabular}{|c|c|c|c|c|c|c|c|c|}
\hline \multirow[t]{2}{*}{ Mix ratio (\%) } & \multicolumn{8}{|c|}{ Dosage $\left(\mathrm{kg} / \mathrm{m}^{3}\right)$} \\
\hline & Tap water & Waste slurry & Cement & Fly ash & Slag powder & Coarse aggregate & Fine aggregate & Additives \\
\hline 0 & 0 & 169 & 390 & 90 & 120 & 1037 & 647 & 11.4 \\
\hline 20 & 33.8 & 135.2 & 390 & 90 & 120 & 1037 & 647 & 11.4 \\
\hline 40 & 67.6 & 101.4 & 390 & 90 & 120 & 1037 & 647 & 11.4 \\
\hline 60 & 101.4 & 67.6 & 390 & 90 & 120 & 1037 & 647 & 11.4 \\
\hline 80 & 135.2 & 33.8 & 390 & 90 & 120 & 1037 & 647 & 11.4 \\
\hline 100 & 169 & 0 & 390 & 90 & 120 & 1037 & 647 & 11.4 \\
\hline
\end{tabular}

Table 2. The mix ratios of type II concrete

\begin{tabular}{ccccccccc}
\hline Mix ratio & \multicolumn{7}{c}{ Dosage $\mathbf{( k g / \mathbf { m } ^ { 3 } )}$} \\
\cline { 2 - 8 }$(\boldsymbol{\%})$ & Tap water & Waste slurry & Cement & Fly ash & Slag powder & Coarse aggregate & Fine aggregate & Additives \\
\hline 0 & 0 & 169 & 420 & 120 & 60 & 1037 & 647 & 11.4 \\
20 & 33.8 & 135.2 & 420 & 120 & 60 & 1037 & 647 & 11.4 \\
40 & 67.6 & 101.4 & 420 & 120 & 60 & 1037 & 647 & 11.4 \\
60 & 101.4 & 67.6 & 420 & 120 & 60 & 1037 & 647 & 11.4 \\
80 & 135.2 & 33.8 & 420 & 120 & 60 & 1037 & 647 & 11.4 \\
100 & 169 & 0 & 420 & 120 & 60 & 1037 & 647 & 11.4 \\
\hline
\end{tabular}




\subsection{XRD tests}

The mixing of waste slurry will affect the microstructure of concrete. Moreover, the work performance, properties, and durability of concrete are influenced by the kinds of raw materials, water-binder ratio, and the type of mineral mixture. Hence, a TD-3500 X-ray diffractometer was adopted to study the effects of different mineral admixtures and waste slurry on the microstructure of concrete samples.

Four groups of concrete samples were prepared for XRD tests. The dosage of cementitious material, and the mix ratios of admixture and concrete were the same. The total amount of absorbed water was reduced by proportion. The mixing conditions of the four sample groups are as follows: 100\% tap water $+0 \%$ waste slurry for Group A of type I concrete; $0 \%$ tap water $+100 \%$ waste slurry for Group B of type I concrete; $100 \%$ tap water $+0 \%$ waste slurry for Group A of type II concrete; $0 \%$ tap water $+100 \%$ waste slurry for Group B of type II concrete.

The samples reaching the curing age were taken out of the curing room and crushed. The $5 \mathrm{~mm}$-diameter samples were ground into $80 \mu \mathrm{m}$ powders. Then, the XRD spectra of samples prepared from different mineral admixtures and waste slurry were obtained at $7 \mathrm{~d}$ and $28 \mathrm{~d}$.

\section{ANALYSIS OF TEST RESULTS}

\subsection{Effects of waste slurry on working performance}

Figures 1 and 2 present the effects of waste slurry from mixing station on the working performance of $\mathrm{C} 80$ concrete prepared with types I and II mineral admixtures, respectively.

The experimental results show that the slump and expansion of C80 concrete gradually decreased with growing content of waste slurry. After the waste slurry content surpassed $60 \%$, type I concrete had faster initial slump and 30min slump losses than type II concrete, and less stable slump change than the latter. Type II concrete exhibited greater slump and expansion than type I concrete. The findings are consistent with Franco's conclusion [6] on how the waste slurry from mixing station affects the working performance of concrete.
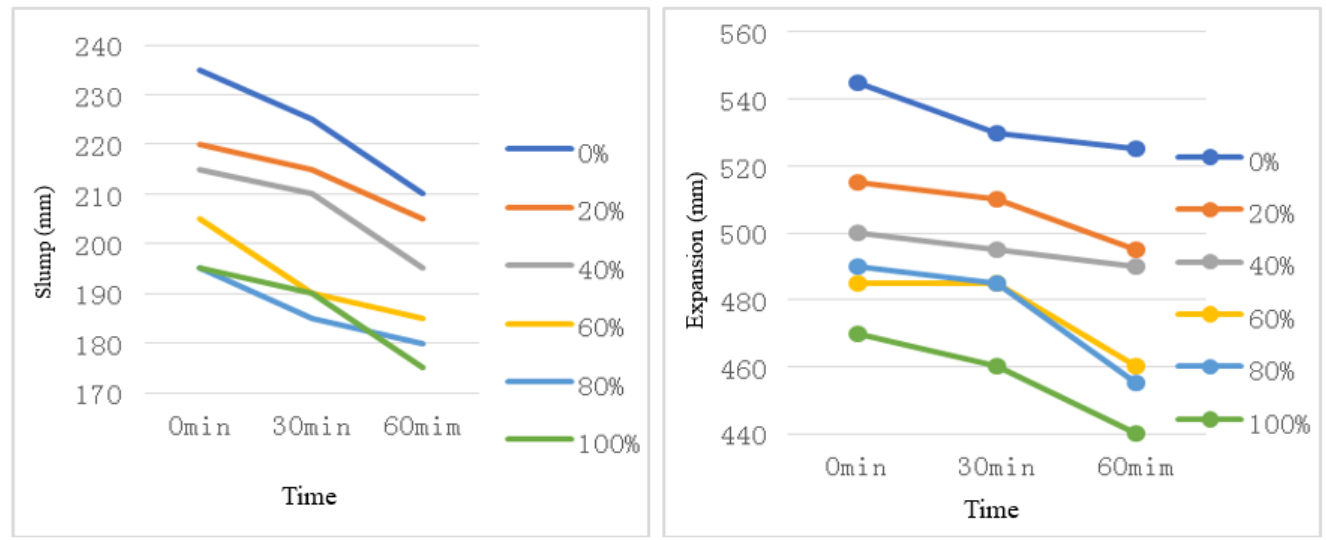

Figure 1. The effects of waste slurry on type I concrete
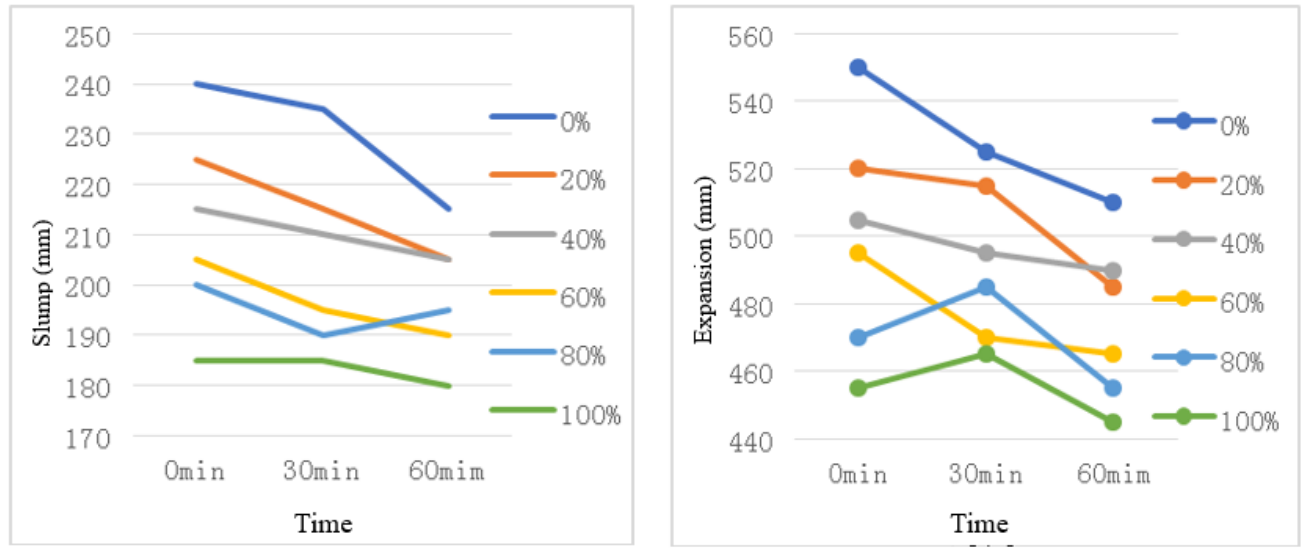

Figure 2. The effects of waste slurry on type II concrete

\subsection{Effects of waste slurry on setting time}

Tables 3 and 4 display the effects of waste slurry from mixing station on the setting time of C80 concrete prepared with types I and II mineral admixtures, respectively. The experimental results demonstrate the influence of waste slurry on the setting time of $\mathrm{C} 80$ concrete prepared from two types of mineral admixtures. With the growing content of waste slurry, the initial and final setting times both gradually increased, but the increments were not significant. This meets the requirements of normal construction. Type II concrete had longer initial and final setting times than type I concrete.

\subsection{Effects of waste slurry on mechanical properties}

Tables 5 and 6 illustrate the effects of waste slurry from mixing station on the compressive strength of C80 concrete prepared with types I and II mineral admixtures, respectively. 
Marco [13] found that the compressive strength of concrete mixed with waste slurry is slightly lower than that of concrete without waste slurry. Li, Xiao and others provided even more experimental results [14-19].

Our experimental results show that, with the growing content of waste slurry, the $7 \mathrm{~d}$ compressive strength of type I concrete stayed below that of reference concrete, and gradually decreased, but the $28 \mathrm{~d}$ and $56 \mathrm{~d}$ compressive strengths increased rapidly. When the waste slurry reached the contents of $20 \%$ and $40 \%$, the $28 \mathrm{~d}$ compressive strength was higher than that of reference concrete.

With the increase of waste slurry content, the $7 d$ compressive strength of type II mineral admixture concrete gradually increased, while the $28 \mathrm{~d}$ and $56 \mathrm{~d}$ compressive strengths increased first and then decreased. When the waste slurry reached the contents of $20 \%$ and $40 \%$, the later compressive strengths were higher than those of the reference concrete.

In comparison, type II concrete has greater compressive strength than type I concrete. The reason lies in the reaction between waste slurry and the specific mineral admixture of each type of concrete. In type I concrete, pozzolanic acid is not highly active in the early phase, and the waste slurry contains some retarding substances. As a result, the concrete has a lower early compressive strength than the reference concrete. In type II concrete, silica fume has higher pozzolanic activity than slag powder in the early phase, and the residual $\mathrm{Ca}(\mathrm{OH})_{2}$ in waste slurry promotes the hydration reaction of silica fume, thereby enhancing the early compressive strength of concrete.

Table 3. The effects of waste slurry on the setting time of type I concrete

\begin{tabular}{cccc}
\hline & $\begin{array}{c}\text { Waste slurry } \\
\text { content (\%) }\end{array}$ & $\begin{array}{c}\text { Initial setting } \\
\text { time (h; min) }\end{array}$ & $\begin{array}{c}\text { Final setting } \\
\text { time (h; min) }\end{array}$ \\
\hline 1 & 0 & $9 \mathrm{~h} 10 \mathrm{~min}$ & $13 \mathrm{~h} 20 \mathrm{~min}$ \\
\hline 2 & 20 & $9 \mathrm{~h} 20 \mathrm{~min}$ & $13 \mathrm{~h} 25 \mathrm{~min}$ \\
3 & 40 & $9 \mathrm{~h} 25 \mathrm{~min}$ & $13 \mathrm{~h} 30 \mathrm{~min}$ \\
4 & 60 & $9 \mathrm{~h} 40 \mathrm{~min}$ & $13 \mathrm{~h} 30 \mathrm{~min}$ \\
5 & 80 & $9 \mathrm{~h} \mathrm{50min}$ & $13 \mathrm{~h} 40 \mathrm{~min}$ \\
6 & 100 & $10 \mathrm{~h} \mathrm{05min}$ & $13 \mathrm{~h} 55 \mathrm{~min}$ \\
\hline
\end{tabular}

Table 4. The effects of waste slurry on the setting time of type II concrete

\begin{tabular}{cccc}
\hline & $\begin{array}{c}\text { Waste slurry } \\
\text { content }(\%)\end{array}$ & $\begin{array}{c}\text { Initial setting } \\
\text { time (h; min) }\end{array}$ & $\begin{array}{c}\text { Final setting } \\
\text { time (h; min) }\end{array}$ \\
\hline 1 & 0 & $9 \mathrm{~h} \mathrm{50min}$ & $15 \mathrm{~h} \mathrm{30min}$ \\
2 & 20 & $9 \mathrm{~h} 55 \mathrm{~min}$ & $15 \mathrm{~h} 40 \mathrm{~min}$ \\
3 & 40 & $10 \mathrm{~h} 10 \mathrm{~min}$ & $15 \mathrm{~h} 45 \mathrm{~min}$ \\
4 & 60 & $10 \mathrm{~h} 25 \mathrm{~min}$ & $15 \mathrm{~h} 45 \mathrm{~min}$ \\
5 & 80 & $10 \mathrm{~h} \mathrm{40min}$ & $15 \mathrm{~h} 55 \mathrm{~min}$ \\
6 & 100 & $10 \mathrm{~h} 55 \mathrm{~min}$ & $15 \mathrm{~h} \mathrm{50min}$ \\
\hline
\end{tabular}

Table 5. The effects of waste slurry on the compressive strength of type I concrete

\begin{tabular}{cccc}
\hline \multirow{2}{*}{ Content } & \multicolumn{3}{c}{ Compressive strength (MPa) } \\
\cline { 2 - 4 } & $7 \mathrm{~d}$ & $28 \mathrm{~d}$ & $56 \mathrm{~d}$ \\
\hline $0 \%$ & 73.6 & 85.4 & 92.3 \\
$20 \%$ & 67.2 & 88.3 & 96.7 \\
$40 \%$ & 66.4 & 87.7 & 98.1 \\
$60 \%$ & 63.1 & 85.2 & 97.5 \\
$80 \%$ & 61.8 & 83.5 & 96.3 \\
$100 \%$ & 59.9 & 82.3 & 96.5 \\
\hline
\end{tabular}

Table 6. The effects of waste slurry on the compressive strength of type II concrete

\begin{tabular}{cccc}
\hline \multirow{2}{*}{ Content } & \multicolumn{3}{c}{ Compressive strength (MPa) } \\
\cline { 2 - 4 } & $7 \mathrm{~d}$ & $28 \mathrm{~d}$ & $56 \mathrm{~d}$ \\
\hline $0 \%$ & 70.0 & 88.4 & 95.3 \\
$20 \%$ & 71.7 & 91.2 & 101.5 \\
$40 \%$ & 73.2 & 92.7 & 102.2 \\
$60 \%$ & 73.9 & 90.6 & 99.4 \\
$80 \%$ & 75.1 & 89.3 & 98.5 \\
$100 \%$ & 77.5 & 89.5 & 98.8 \\
\hline
\end{tabular}

\subsection{Effects of waste slurry on durability}

In general, high-performance concretes are prepared with raw materials of good particle size distribution and a low water-binder ratio, using methods like full vibration to reduce voids. The treatment methods prevent water penetration, making the concrete impermeable. Tables 7 and 8 show the effects of waste slurry from mixing station on the chloride ion penetration (CIP) resistance of C80 concrete prepared with types I and II mineral admixtures, respectively.

The experimental results show that the CIP resistance of C80 concrete was less than $1,000 \mathrm{C}$, which was improved by the addition of waste slurry. Type II concrete had better CIP resistance than type I concrete.

Overall, the solid content of waste slurry has a clear negative impact on the working performance and strength of concrete. But the durability of concrete is not significantly affected, because the solid substances make the concrete more compact.

Table 7. The effects of waste slurry on the CIP resistance of type I concrete

\begin{tabular}{ccccc}
\hline \multirow{2}{*}{ Content (\%) } & \multicolumn{3}{c}{ Electric flux (C) } & \multirow{2}{*}{ Mean (C) } \\
\cline { 2 - 4 } & Group 1 & Group 2 & Group 3 & \\
\hline 0 & 195.7 & 207.8 & 197.7 & 200.4 \\
20 & 166.6 & 165.4 & 178.9 & 170.3 \\
40 & 197.1 & 197.9 & 194.5 & 196.5 \\
60 & 215.5 & 209.8 & 220.9 & 215.4 \\
80 & 233.6 & 226.2 & 227.8 & 229.2 \\
100 & 244.3 & 247.8 & 249.2 & 247.1 \\
\hline
\end{tabular}

Table 8. The effects of waste slurry on the CIP resistance of type II concrete

\begin{tabular}{ccccc}
\hline \multirow{2}{*}{ Content (\%) } & \multicolumn{3}{c}{ Electric flux (C) } & \multirow{2}{*}{ Mean (C) } \\
\cline { 2 - 4 } & Group 1 & Group 2 & Group 3 & \\
\hline 0 & 167.5 & 177.1 & 168.1 & 170.9 \\
20 & 150.1 & 149.3 & 157.8 & 152.4 \\
40 & 144.4 & 143.2 & 158.5 & 148.7 \\
60 & 143.2 & 157.6 & 149.8 & 150.2 \\
80 & 150.9 & 153.2 & 164.8 & 156.3 \\
100 & 163.6 & 161.6 & 160.9 & 163.6 \\
\hline
\end{tabular}

\subsection{Effects of waste slurry on carbonation resistance}

Li [16] called for more research on the influence of waste slurry on the durability of concrete. Xiao [17] found that, with the increase of waste slurry content, the early carbonation depth does not change much, but the later carbonation depth increases to a certain extent.

In our experiments, the carbonization depths of the two types of concretes were zero, indicating that the addition of waste slurry increases the compactness of concrete. This is 
because the residual fine particles in waste slurry fill the voids of concrete. This finding echoes with the conclusions of Rickert et al. and Chatveera and Lertwattanaruk [20, 21].

\subsection{Effects of waste slurry on microstructure}

Figures 3 and 4 provide the 7d XRD spectra of type 1 and type 2 concrete samples, respectively. Figures 5 and 6 provide the $28 \mathrm{~d}$ XRD spectra of type 1 and type 2 concrete samples, respectively.

From Figures 3-6, it can be seen that, for both types of concrete samples, the $7 \mathrm{~d}$ XRD peak of using tap water as mixing water was slightly higher than that of using waste slurry as mixing water; the $28 \mathrm{~d}$ XRD peak of the former was slightly lower than that of the latter.

For the concrete samples prepared from fly ash and slag powder, the fly ash is not highly active in the early phase. The $\mathrm{pH}$ of tap water is lower than that of waste slurry, owing to the alkaline residual substances in the slurry. The addition of waste slurry inhibits the hydration of cement in the early phase. That is why the XRD peak of using tap water as mixing water was slightly higher than that of using waste slurry as mixing water.

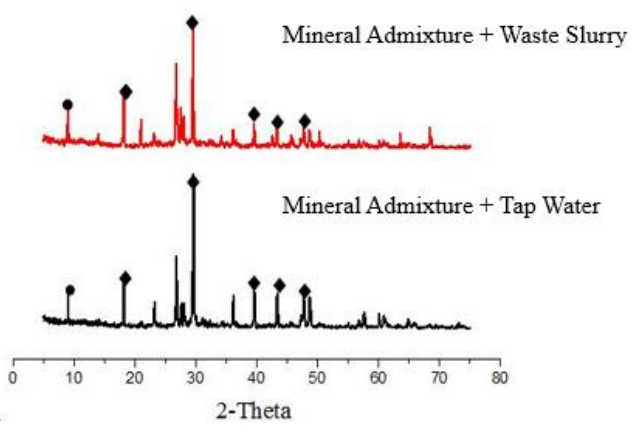

Figure 3. The $7 \mathrm{~d}$ XRD spectra of type 1 concrete samples

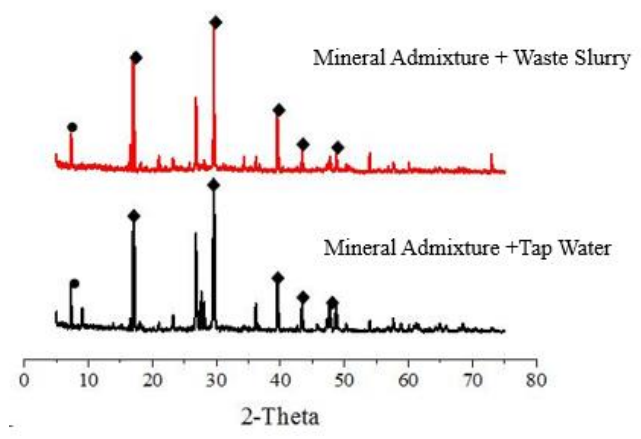

Figure 4. The 7d XRD spectra of type 2 concrete samples

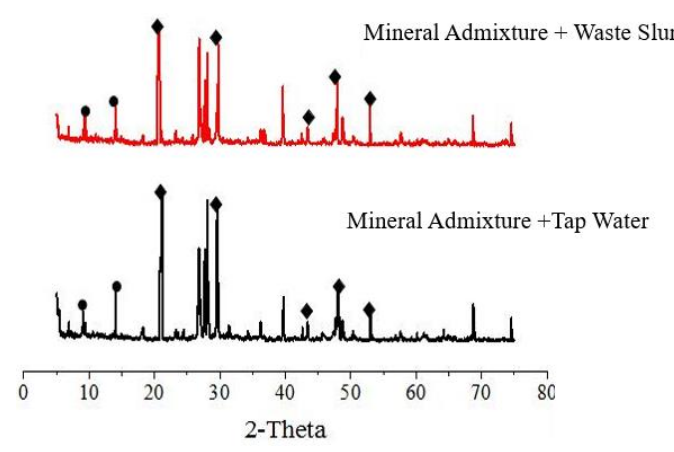

Figure 5. The 28d XRD spectra of type 1 concrete samples

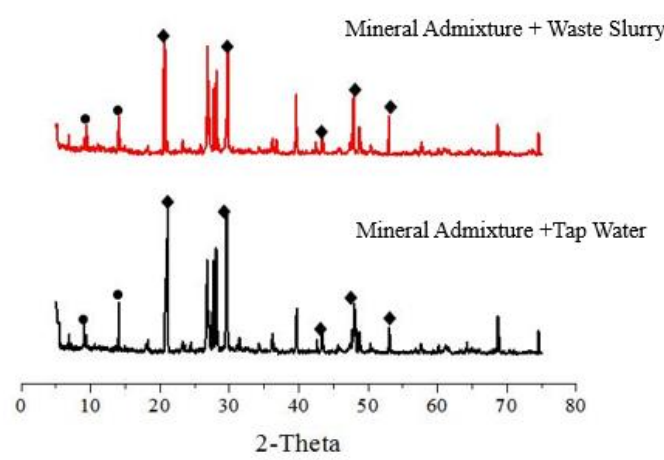

Figure 6. The $28 \mathrm{~d}$ XRD spectra of type 2 concrete samples

For the concrete samples prepared from fly ash and silica fume, each sample has high early pozzolanic activity, and hydrates faster thanks to the $\mathrm{Ca}(\mathrm{OH})_{2}$ in the waste slurry. As a result, the XRD peak of using tap water as mixing water was slightly lower than that of using waste slurry as mixing water.

Fly ash mixed with slag powder and silica fume help to reduce porosity and improve compactness. The waste slurry is strongly alkaline, which gives play to the later activity of slag powder and produces stable hydration products. Many scholars [18-21] held that the concrete mixed with waste slurry is stronger than that mixed with tap water.

\section{CONCLUSION}

(1) The slump and expansion of C80 concrete gradually decreased with growing content of waste slurry. After the waste slurry content surpassed $60 \%$, type I concrete had faster initial slump and 30min slump losses than type II concrete, and less stable slump change than the latter.

(2) With the growing content of waste slurry, the initial and final setting times both gradually increased, but the increments were not significant. This meets the requirements of normal construction. Type II concrete had longer initial and final setting times than type I concrete.

(3) With the growing content of waste slurry, the $7 d$ compressive strength of type I concrete stayed below that of reference concrete, and gradually decreased, but the later compressive strengths increased rapidly; the $7 \mathrm{~d}$ compressive strength of type II mineral admixture concrete gradually increased, while the later compressive strengths increased first and then decreased.

(4) Mixing waste slurry improves the permeability and carbonation resistance of concrete. Type II concrete had better CIP resistance than type I concrete. The carbonization depths of the two types of concretes were zero, indicating that the addition of waste slurry increases the compactness of concrete.

(5) The 7d XRD peak of using tap water as mixing water was slightly higher than that of using waste slurry as mixing water; the $28 \mathrm{~d}$ XRD peak of the former was slightly lower than that of the latter.

\section{ACKNOWLEDGMENTS}

This work was supported by Major Natural Science Research Project of Universities in Anhui, China (Grant No.: KJ2018ZD054). 


\section{REFERENCE}

[1] Mahesh, V., Joladarashi, S., Kulkarni, S.M. (2018). Experimental investigation on slurry erosive behaviour of biodegradable flexible composite and optimization of parameters using Taguchi's approach. Revue des Composites et des Matériaux Avancés, 28(3): 345-355. https://doi.org/10.3166/RCMA.28.345-355

[2] He, X.Y., Zheng, Z.Q., Ma, M.Y., Su, Y., Yang, J., Tan, H.B., Wang, Y.B., Strnadel, B. (2020). New treatment technology: The use of wet-milling concrete slurry waste to substitute cement. Journal of Cleaner Production, 242: 118347. https://doi.org/10.1016/j.jclepro.2019.118347

[3] Karthik, D.E., Mrudunayani, P., Babu, S.V.V.K. (2019). Influence of magnetic water on self-compacting concrete using sulphate resisting cement. Annales de Chimie: Science des Matériaux, 43(5): 347-352. https://doi.org/10.18280/acsm.430511

[4] Jiang, W. (2018). Study on the influence of fly ash and mineral powder on the performance and strength of concrete. Shandong Industrial Technology, 37(22): 6985.

[5] Zhao, T.W., Zeng, Y., Zhu, B., Li, C.B., Zhan, Z.F., Zhou, X.Q. (2018). Discussion on the recycling of waste water and waste residue in concrete mixing station. Guangdong Building Materials, 34(9): 9-11. https://doi.org/10.3969/j.issn.1009-4806.2018.09.004

[6] Sandrolini, F., Franzoni, E. (2001). Waste wash water recycling in ready-mixed concrete plants. Cement and Concrete Research, 31(3): 485-489. https://doi.org/10.1016/s0008-8846(00)00468-3

[7] Li, J., Liu, Z. (2011). Microanalysis of recycled coarse aggregate and properties of no-fines pervious recycled concrete. Journal of Testing and Evaluation, 39(5): 766772. https://doi.org/10.1520/JTE103417

[8] Al-Zboon, K., Al-Zou'by, J. (2015). Recycling of stone cutting slurry in concrete mixes. Journal of Material Cycles and Waste Management, 17(2): 324-335. https://doi.org/10.1007/s10163-014-0246-x

[9] Ministry of Housing and Urban-Rural Development of the People's Republic of China. GB/T50080-2016, Standard for Test Method of Performance on Ordinary Fresh Concrete. Published by China Building Industry Press: Beijing (2017), in Chinese.

[10] Ministry of Housing and Urban-Rural Development of the People's Republic of China. GB/T50081-2019, Standard for Test Methods of Mechanical Properties on Ordinary Concrete. Published by China Building Industry Press: Beijing (2019), in Chinese.
[11] High Strength and High Performance Concrete Committee of China Civil Engineering Society.CECS104: 99, Technical Specification for HighStrength Concrete Structures. China Engineering Construction Standardization Association: Beijing (1999), in Chinese.

[12] Ministry of Housing and Urban-Rural Development of the People's Republic of China. GB/T50082-2009, Test Method for Long-term and Durability of Ordinary Concrete. Published by China Building Industry Press: Beijing (2009), in Chinese.

[13] Paolini, M., Khurana, R. (1998). Admixtures for recycling of waste concrete. Cement \& Concrete Composites, 20(2-3): 221-229. https://doi.org/10.1016/S0958-9465(97)00066-8

[14] Li, X.L., He, T.S. (2011). Effects of mixing station recirculating water on the properties of cement-based materials. $\quad$ Concrete, 33(3): 139-141. https://doi.org/10.1097/RLU.0b013e3181f49ac7

[15] Xiao, J., Gou, C.F. (2010). Review of the research for concrete carbonation. Concrete, 32(1): 40-44, 52. https://doi.org/10.3969/j.issn.1002-3550.2010.01.014

[16] Singh, M., Srivastava, A., Bhunia, D. (2019). Long term strength and durability parameters of hardened concrete on partially replacing cement by dried waste marble powder slurry. Construction and Building Materials, 198: 553-569. https://doi.org/10.1016/j.conbuildmat.2018.12.005

[17] He, X., Zheng, Z., Yang, J., Su, Y., Wang, T., Strnadel, B. (2020). Feasibility of incorporating autoclaved aerated concrete waste for cement replacement in sustainable building materials. Journal of Cleaner Production, 250: 119455. https://doi.org/10.1016/j.jclepro.2019.119455

[18] Wang, R., Zhang, Y.X. (2018). Recycling fresh concrete waste: A review. Structural Concrete, 19(6): 1939-1955. https://doi.org/10.1002/suco.201800057

[19] Ouyang, M.X., Li, Y.P., Zhang, K.F., Meng, G., Wu, X. (2013). Experimental study on the preparation of C20C40 green concretes by waste water from concrete batching plant. Concrete, 35(11): 124-125, 129

[20] Rickert, J.R., Grube, H., Zeng, X.H., et al. (2005). Influence of recycled water in mixing plant on concrete performance. Ready-mixed Concrete, 2(4): 53-61.

[21] Chatveera, B., Lertwattanaruk, P. (2009). Use of readymixed concrete plant sludge water in concrete containing an additive or admixture. Journal of Environmental Management, $\quad$ 90(5): 1901-1908. https://doi.org/10.1016/j.jenvman.2009.01.008 